\title{
Depression during pregnancy and the postpartum period in adolescent and adult Portuguese mothers
}

\author{
B. Figueiredo, A. Pacheco, and R. Costa \\ Department of Psychology, University of Minho, Braga, Portugal
}

Received April 6, 2006; accepted February 27, 2007

Published online May 18, 2007 (C) Springer-Verlag 2007

\begin{abstract}
Summary
Objective: To study prevalence as well as risk factors for pregnancy and postpartum depression in a sample of adolescent and adult Portuguese mothers.

Methods: The Edinburgh Postnatal Depression Scale (EPDS) was administered to 108 (54 adult and 54 adolescent) Portuguese women at 24-36 weeks of pregnancy and at 2-3 months postpartum.

Results: Rates for EPDS $>12$ are high during the $3^{\text {rd }}$ trimester of pregnancy $(18.5 \%)$ and at 2-3 months postpartum (17.6\%), and not significantly different between these two periods; more than $1 / 4$ of the sample $(27.8 \%)$ had an EPDS $>12$ before or after delivery. Adolescent mothers presented more depressive symptoms as well as more EPDS $>12$ than adult mothers, both in pregnancy $(25.9 \%$ versus $11.1 \%$ ) and at $2-3$ months postpartum (25.9\% versus $9.3 \%)$; moreover, when considering other socio-demographics, adolescent mothers were still at risk for depressive symptoms during pregnancy as well as for postpartum depression. Women depressed in pregnancy, and ones who are under 18 years old and who live with the partner, were at risk for postpartum EPDS $>12$.

Conclusion: Adolescent mothers seem particularly at risk for depression during pregnancy and the postpartum period, therefore, just like the women who are depressed during pregnancy, they should be better targeted in preventive and intervention measures.
\end{abstract}

Keywords: Adolescent mothers; EPDS; Portuguese women; postpartum depression; pregnancy depression.

\section{Introduction}

The incidence of depression during pregnancy is quite high (10-20\%), as reported in several studies carried out in different parts of the world (e.g., Andersson et al, 2003; Chung et al, 2001; Gorman et al, 2004; Josefsson et al, 2001; Limlomwongse \& Liabsuetrakul, 2006; Marcus et al, 2003). Predictors for women's depres- sion during pregnancy have received large agreement in literature, namely: less favorable socio-demographics (for example, being unemployed and single) (e.g., Limlomwongse \& Liabsuetrakul, 2006); previous history of depression (e.g., Marcus et al, 2003; RichEdwards et al, 2006); adverse life events, low levels of social support and problems in close relationships (e.g., Figueiredo et al, 2006; McKee et al, 2001; Pajulo et al, 2001; Seguin et al, 1995; Zuckerman et al, 1989).

The incidence of postpartum depression is high as well (13\%, as it appears in O'Hara and Swain's (1996) meta-analysis of 59 studies), and data collected more recently confirm this in several different countries (e.g., Adouard et al, 2005; Agoub et al, 2005; Boyce et al, 2000; Felice et al, 2006; Seimyr et al, 2004; Thome, 2000; Verkek et al, 2003). Predictors for postpartum depression have also received consistent agreement in literature. For example, factors of increased risk for postpartum depression were studied in a sample of over 6000 pregnant women and grouped according to the 3 following aspects: negative physical or emotional pregnancy experience, previous history of mood disorder, and lack of or difficulties in close relationships (Cooper et al, 1996). In addition to antenatal factors, infant irritability and poor motor development as well as maternal mood after delivery increase the risk for postpartum depression (Murray et al, 1996). Other studies present the same associated factors (e.g., Agoub et al, 2005), but more recently pregnancy depression has been pointed out as the main risk factor for postpartum depression 
(e.g., Hobfoll et al, 2005; Kitamura et al, 2006; RichEdwards et al, 2006).

Rates for depression in Portugal seem to be quite similar to the ones of other countries, either in pregnancy or the postpartum period: $9.5 \%$ of the Portuguese women were depressed (EPDS $>12$ ) before delivery and 9.4\% after delivery in a recent European comparative study (Gorman et al, 2004). In other studies, 16.7\% (Areias et al, 1996b), 13.1\% (Augusto et al, 1996) and $13.7 \%$ (Costa et al, 2007) of the women scored above the cut-off value at 2-3 months postpartum. Also, similar risk factors for postpartum depression have appeared in Portuguese samples, namely: history of depression or depression during pregnancy, socio-economic stressors, parity, negative delivery experience and lack of support or difficulties in close relationships (Areias et al, 1996b; Augusto et al, 1996; Costa et al, 2007).

Even so, when women living in underprivileged circumstances are targeted, rates for depression during pregnancy and the postpartum period are significantly higher, seeing that about $25-50 \%$ of them show depressive symptoms at a clinical level before and/or after delivery (e.g., Hobfoll et al, 2005; McKee et al, 2001; Onozawa et al, 2003; Rich-Edwards et al, 2006; Schmidt et al, 2006; Seguin et al, 1995). Adolescent mothers are reported as being at high risk for pregnancy and postpartum depression (Barnet et al, 1996; Colleta, 1983; Deal \& Holtz, 1998; Hudson et al, 2000; Leadbeater \& Linares, 1992; Prodromidis et al, 1994; Rich-Edwards et al, 2006; Schmidt et al, 2006; Troutman \& Cutrona, 1990), taking into consideration that the younger the mother the greater the risk for depression (McGee et al, 1983). Some studies have pointed out that one in two pregnant adolescents is going to be depressed after delivery (e.g., Leadbeater \& Linares, 1992; Schmidt et al, 2006). Moderate to severe depressive symptoms were found in $36.7 \%$ of the sample 3 months after delivery in a recent study of 623 adolescent mothers, 18-year old or younger (Schmidt et al, 2006). However, socio-demographics were usually not taken into consideration when comparing adolescent with adult mothers and the incidence for depression during pregnancy is relatively unknown in this specific population. Some findings suggest that pregnant adolescents are less distressed than they seem to be; the reason why they get depressed derives from aspects other than age, but highly associated with adolescent pregnancy (e.g., Figueiredo et al, 2006). Also, parenting status does not predict the adolescent's psychological well-being when comparing pregnant and non pregnant teenagers (e.g., Barth et al, 1983; Millan et al, 2004; Troutman \& Cutrona, 1990). Young maternal age has been associated with greater risk of antenatal and postpartum symptoms, but, in a recent study, that was largely attributable to the prevalence of financial problems, unwanted pregnancy and lack of a partner (Rich-Edwards et al, 2006).

Prospective studies focusing the prevalence of depression during pregnancy and the first postpartum months have noticed in addition: (1) more depressed women or stronger depressive symptoms in women before than after delivery (e.g., Limlomwongse \& Liabsuetrakul, 2006); (2) half of the depressed women during pregnancy remained depressed during the postpartum period (e.g., Gorman et al, 2004; Josefsson et al, 2001; Marcus et al, 2003); and (3) usually postpartum depressed women were already depressed during pregnancy (Da Costa et al, 2000; Evans et al, 2001; Johanson et al, 2000; Josefsson et al, 2001). These empirical results are contradictory with some previous ones (e.g., Kumar \& Robson, 1984; Ritter et al, 2000), and have even further stressed the need for screening for depression in women during pregnancy.

Recent empirical findings are somewhat contradictory regarding previous reports covering the following aspects, which the present study would like to help clarify: Is depression more prevalent in women during pregnancy or the postpartum period? Can postpartum depression be predicted by depression during pregnancy? Are adolescents at higher risk for depression than adult women before and after delivery when socio-demographics are taken into consideration?

The main objective is to study pregnancy and postpartum depression in adolescent and adult Portuguese women, with emphasis on (1) prevalence of depressive symptoms and EPDS $>12$ in pregnancy and the postpartum period, namely differences in rates of depression between pregnancy and the postpartum period and differences in rates of depression between adolescent and adult women; (2) socio-demographic risk factors for depressive symptoms and EPDS $>12$ during the $3^{\text {rd }}$ trimester of pregnancy and at 2-3 months postpartum.

\section{Participants and method}

\section{Participants}

The sample was composed of 108 (54 adult and 54 adolescent) pregnant women, aged between 14 and 40 years old (mean = 22.83, SD =7.26); most of them Portuguese (94.6\%), Caucasian (98.1\%) and primiparous $(72.2 \%)$. As you can see in Table 1, participants were equally employed and unemployed, but generally had less than 9 years of education, were married or coha- 
Table 1. Socio-demographics

\begin{tabular}{|c|c|c|c|c|}
\hline Socio-demographics & $\begin{array}{l}\text { Total } \\
n=108 \\
\%\end{array}$ & $\begin{array}{l}\text { Adolescent } \\
n=54 \\
\%\end{array}$ & $\begin{array}{l}\text { Adult } \\
n=54 \\
\%\end{array}$ & $\chi^{2}$ \\
\hline \multicolumn{5}{|l|}{ Education } \\
\hline$<$ grade 9 & 73.1 & 87.0 & 59.3 & \multirow[t]{2}{*}{$10.607^{* *}$} \\
\hline$\geq$ grade 9 & 26.9 & 13.0 & 40.7 & \\
\hline \multicolumn{5}{|l|}{ Marital status } \\
\hline Married or cohabiting & 72.2 & 48.1 & 96.3 & \multirow[t]{2}{*}{$31.200^{* * *}$} \\
\hline Single & 27.8 & 51.9 & 3.7 & \\
\hline \multicolumn{5}{|l|}{ Employment status } \\
\hline Employed & 50.0 & 17.3 & 81.5 & \multirow[t]{2}{*}{$43.638^{* * *}$} \\
\hline Unemployed & 50.0 & 82.7 & 18.5 & \\
\hline \multicolumn{5}{|l|}{ Family unit } \\
\hline With family of origin & 73.1 & 83.3 & 63.0 & \multirow[t]{2}{*}{$5.704^{*}$} \\
\hline Without family of origin & 26.9 & 16.7 & 37.0 & \\
\hline \multicolumn{5}{|l|}{ Partner employment status } \\
\hline Employed & 85.9 & 72.9 & 98.0 & \multirow[t]{2}{*}{$12.854^{* * *}$} \\
\hline Unemployed & 14.1 & 27.1 & 2.0 & \\
\hline \multicolumn{5}{|l|}{ Parity } \\
\hline Primiparous & 72.2 & 97.2 & 75.0 & \multirow[t]{2}{*}{$26.585^{* * *}$} \\
\hline Multiparous & 27.8 & 2.8 & 25.0 & \\
\hline
\end{tabular}

${ }^{*} \mathrm{p}<0.05 ;{ }^{* *} \mathrm{p} \leq 0.01 ;{ }^{* * *} \mathrm{p} \leq 0.000$.

biting, and living with their family of origin; the partner usually belonged to the family aggregate $(72.2 \%)$ and was employed.

Adolescent mothers $(\leq 18$-year old) presented with more unfavourable socio-demographics than adult mothers, as they usually did not have grade 9 , were unemployed, were neither married nor cohabiting with the partner, but living with the family of origin, and their partners were also more frequently unemployed. Almost all the adolescent mothers were primiparous compared to adult mothers who were both primiparous and multiparous.

\section{Measures}

A socio-demographic questionnaire was used to collect data concerning the pregnant women and their partners: age, place of birth, parity, education, occupation, marital status, family aggregate, etc.

The Portuguese version (Augusto et al, 1996) of the Edinburgh Postnatal Depression Scale (EPDS, Cox et al, 1987), a selfreport questionnaire composed of 10 items scored in a 4-point likert scale (0-3), was administered to assess pregnancy and postpartum depression. This questionnaire addresses the intensity of depressive symptoms within the previous seven days, and has been used in several studies both with pregnant (Da Costa et al, 2000; Rich-Edwards et al, 2006; Ross et al, 2003) and postpartum women (e.g., Adouard et al, 2005, Agoub et al, 2005; Limlomwongse \& Liabsuetrakul, 2006), including Portugal (Areias et al, 1996a, b; Augusto et al, 1996; Costa et al, 2007; Figueiredo et al, 2006). EPDS Portuguese version showed good internal consistency $($ Cronbach Alpha $=0.85)$, test-retest reliability $(r=0.75)$, and external validity having the SADS psychiatric interview as a criterion $(r=0.86)$ (Figueiredo, 1997). A score higher than 12 indicates the probable presence of a major depressive episode (Areias et al, 1996b; Augusto et al, 1996).

\section{Procedures}

All participants were randomly selected before their routine medical appointment at the Júlio Dinis Maternity Hospital (MJD, Porto, Portugal), attending with their gestational age (24-36 weeks). The pregnant women were informed about the study's aims, and signed an informed consent when they agreed to participate ( $81.8 \%$ of the approached women agreed to participate). Socio-demographics were collected and the mothers had filled in the EPDS after the medical appointment. All mothers completed the scale again at the 2-3 months postpartum medical appointment. Ethical permission was obtained from the MJD Hospital Ethical Commission.

\section{Statistical analyses}

To evaluate differences between pregnancy and postpartum EPDS $>12$ a Wilcoxon paired samples $t$-test was used. To examine means differences in EPDS results between pregnancy versus postpartum and between adolescent versus adult mothers, paired and independent samples $t$-tests were respectively performed. Chi-squares were performed to examine differences in EPDS $>12$ and socio-demographics between adolescent versus adult mothers.

Multiple linear regression analyses were used to identify predictors of a mother's depressive symptoms in the $3^{\text {rd }}$ trimester of pregnancy and at 2-3 months postpartum, using as independent variables: age, educational level $(</ \geq$ grade 9), employment status (employed/unemployed), living or not with the partner, living or not with the family of origin, parity (primiparous/ multiparous), and depression in pregnancy (EPDS $\leq />12$ ) (only for postpartum prediction). The same set of variables was applied in multiple logistic regression analyses to identify risk factors for pregnancy and postpartum EPDS $>12$.

\section{Results}

Rates for depressive symptoms and EPDS $>12$

during pregnancy and the postpartum period in adolescent and adult mothers

As can be seen in Table 2:

Rates for EPDS $>12$ are high both during the $3^{\text {rd }}$ pregnancy trimester $(18.5 \%)$ and the $2^{\text {nd }}-3^{\text {rd }}$ postpartum month (17.6\%), with no significant differences in EPDS $>12$ between these two periods $(\mathrm{Z}(2)=0.218, p=0.827)$. Mean differences for depressive symptoms in pregnancy and the postpartum period were also not significant: women report similar levels of depressive symptoms during these two periods $(t=1.173, p=0.243)$.

More than one in four women $(27.8 \%)$ are depressed at least at one point, before or after delivery, and some of them $(8.3 \%)$ are depressed at both times, before and after delivery. Almost half of the depressed women during the last trimester of pregnancy (45.0\%) remained depressed at 2-3 months postpartum, and al- 
Table 2. Rates for depressive symptoms and for EPDS $>12$ during pregnancy and the postpartum period in adolescent and adult mothers

\begin{tabular}{|c|c|c|c|c|c|c|}
\hline & \multicolumn{2}{|c|}{$\begin{array}{l}\text { Pregnancy }(n=108) \\
(\text { adolescent }=54, \text { adult }=54)\end{array}$} & \multicolumn{2}{|c|}{$\begin{array}{l}\text { Postpartum }(n=108) \\
(\text { adolescent }=54, \text { adult }=54)\end{array}$} & \multirow{2}{*}{$\begin{array}{l}\text { Pregnancy and } \\
\text { postpartum }(n=108) \\
(\text { adolescent }=54, \\
\text { adult }=54) \\
\text { EPDS }>12(\%)\end{array}$} & \multirow{2}{*}{$\begin{array}{l}\text { Pregnancy or } \\
\text { postpartum }(n=108) \\
(\text { adolescent }=54, \\
\text { adult }=54) \\
\text { EPDS }>12(\%)\end{array}$} \\
\hline & EPDS $>12(\%)$ & Mean $(S D)$ & EPDS $>12(\%)$ & Mean $(S D)$ & & \\
\hline Adolescent & 25.9 & 9.44 (5.69) & 25.9 & $8.54(5.98)$ & 16.7 & 35.2 \\
\hline Adult & 11.1 & $6.46(3.97)$ & 9.3 & $6.30(4.65)$ & 0 & 20.4 \\
\hline Total & 18.5 & $7.95(5.11)$ & 17.6 & $7.42(5.45)$ & 8.3 & 27.8 \\
\hline
\end{tabular}

most half of the postpartum depressed women (47.4\%) were already depressed during the $3^{\text {rd }}$ trimester of pregnancy.

When adolescent and adult mothers were compared, significant differences were obtained, with more cases of EPDS $>12$ in the adolescent group, both in pregnancy $\left(\chi^{2}(1)=3.927, p=0.041\right)$ and the postpartum period $\left(\chi^{2}(1)=5.173, p=0.021\right)$. Moreover, adolescent women have significantly more depressive symptoms than adults both before $(t=4.461, p=0.002)$ and after delivery $(t=5.766, p=0.032)$. Also, all cases of EPDS $>12$ in pregnancy and the postpartum period belonged to the adolescent mother group $\left(\chi^{2}(1)=9.818, p=\right.$ 0.001 ), and a marginally significant difference was obtained between adolescent and adult women for EPDS $>12$ in pregnancy or in the postpartum period $\left(\chi^{2}(1)=2.954, p=0.066\right)$.

Risk factors for depressive symptoms and for EPDS $>12$ during pregnancy and the postpartum period

Pregnancy

When all the studied socio-demographics were considered as risk factors for depressive symptoms during the $3^{\text {rd }}$ pregnancy trimester (stepwise method), age was the best and only predictor; results show that the younger the mother the higher her EPDS pregnancy result $\left(\mathrm{R}^{2}=0.082, \mathrm{~B}=-0.286, \mathrm{~F}[1,104]=9.272, p=0.003\right)$. When all the socio-demographic variables but not age were considered for the equation (stepwise method model 1), cohabitation status was the best and only predictor, explaining $5.2 \%$ of the variance in pregnancy EPDS results, with women living without the partner having higher EPDS results $\left(\mathrm{R}^{2}=0.052, \mathrm{~B}=0.228\right.$, $\mathrm{F}[1,104]=5.679, p=0.019)$; but age (model 2$)\left(\Delta \mathrm{R}^{2}=\right.$ $0.042, p=0.32)$ significantly explained some of the remaining variance $\left(\mathrm{R}^{2}=0.093, \mathrm{~B}=-0.230, \mathrm{~F}[2,103]=\right.$ 5.298, $p=0.006$ ).

However, neither age nor the other socio-demographic variables considered could explain significantly an EPDS $>12$ in pregnancy, as can be seen in Table 3 .

\section{Postpartum}

When all the studied socio-demographics were considered as risk factors for depressive symptoms at 2-3 months postpartum (stepwise method), pregnancy EPDS $>12$ was the best predictor accounting for $24.9 \%$ of the vari-

Table 3. Risk factors for EPDS $>12$ during pregnancy and the postpartum period (logistic regression analysis)

\begin{tabular}{|c|c|c|c|c|c|}
\hline Model & Variables & $\mathrm{B}$ & OR & $95 \%$ IC & $P$ \\
\hline Pregnancy & age $\geq 18$ & -1.287 & 0.276 & $0.049-1.547$ & 0.143 \\
\hline \multirow[t]{5}{*}{$\left(\chi^{2}(6)=5.131, p=0.527\right)$} & $>$ grade 9 & -0.397 & 0.672 & $0.161-2.798$ & 0.585 \\
\hline & employed & 0.290 & 1.336 & $0.341-5.243$ & 0.678 \\
\hline & living with partner & -0.336 & 0.715 & $0.167-3.057$ & 0.650 \\
\hline & not living with family of origin & 0.153 & 1.165 & $0.241-5.627$ & 0.849 \\
\hline & primiparous & -0.697 & 0.498 & $0.090-2.761$ & 0.425 \\
\hline \multicolumn{6}{|l|}{ Goodness of fit $=82.1 \%$} \\
\hline \multirow{7}{*}{$\begin{array}{l}\text { Postpartum } \\
\qquad\left(\chi^{2}(7)=26.513, p=0.000\right)\end{array}$} & age $\geq 18$ & -3.287 & $\mathbf{0 . 0 3 7}$ & $0.003-0.417$ & 0.008 \\
\hline & $>$ grade 9 & 1.560 & 4.759 & $0.954-23.734$ & 0.057 \\
\hline & employed & 0.548 & 1.730 & $0.381-7.858$ & 0.478 \\
\hline & living with partner & 1.658 & 5.251 & $0.993-27.769$ & 0.051 \\
\hline & not living with family of origin & -1.715 & 0.180 & $0.024-1.343$ & 0.094 \\
\hline & primiparous & -1.252 & 0.286 & $0.035-2.322$ & 0.241 \\
\hline & no pregnancy depression & -2.257 & 0.105 & $0.026-0.423$ & 0.002 \\
\hline Goodness of fit $=\mathbf{8 5 . 8 \%}$ & & & & & \\
\hline
\end{tabular}


ance in postpartum EPDS results $\left(\mathrm{R}^{2}=0.249, \mathrm{~B}=0.499\right.$, $\mathrm{F}[1,104]=34.502, p=0.000)$; living with the family of origin was also associated with an increase in EPDS results $(\mathrm{B}=0.252)$, and these two variables explain $31.2 \%\left(\mathrm{R}^{2}=0.312, \mathrm{~F}[2,103]=23.386, p=0.000\right)$ of the variance in postpartum EPDS results. But not age, which was not included in the predictive equation after the entry of all the other considered variables (model 2) $\left(\mathrm{R}^{2}=0.312, \mathrm{~F}[3,102]=15.450, p=0.000\right)$, and didn't explain significantly any supplementary variance $\left(\Delta R^{2}=\right.$ $0.000, p=0.883$ ).

Moreover, as can be seen in Table 3, the risk for having a postpartum EPDS $>12$ is significantly higher when the mother is living with the partner, is less than 18 years old and was already depressed during pregnancy.

\section{Discussion and conclusion}

Levels of depressive symptoms as well as rates for EPDS $>12$ were high in this Portuguese sample, both during the $3^{\text {rd }}$ trimester of pregnancy $(17.6 \%)$ and the $2^{\text {nd }}-3^{\text {rd }}$ postpartum month $(18.5 \%)$. It's particularly relevant that more than $1 / 4$ of the participants $(27.8 \%)$ were depressed at least within one of the two target points. Levels of depressive symptoms as well as rates for EPDS $>12$ were similarly high in pregnancy and the postpartum period. These results suggest, in accordance with recent literature, that women are at high risk for depression before, in addition to after delivery (Andersson et al, 2003; Marcus et al, 2003), and that pregnancy depression is as common as postpartum depression (e.g., Gorman et al, 2004).

Adolescent mothers presented more depressive symptoms as well as more EPDS $>12$ than adult mothers, both in pregnancy $(25.9 \%$ versus $11.1 \%)$ and in the postpartum period ( $25.9 \%$ versus $9.3 \%)$; also, all cases of EPDS $>12$ in pregnancy and the postpartum period were due to the adolescent mother group. These results suggest that adolescent mothers are particularly at risk for pregnancy and postpartum depression, in similar rates $(25-50 \%)$ as it had been pointed out in other samples of adolescent mothers (Barnet et al, 1996; Colleta, 1983; Deal \& Holtz, 1998; Hobfoll et al, 2005; Hudson et al, 2000; Leadbeater \& Linares, 1992; Prodromidis et al, 1994; Rich-Edwards et al, 2006; Schmidt et al, 2006; Troutman \& Cutrona, 1990). Presented results also suggest that adolescent mothers can be at risk for depressive symptoms during pregnancy as well as for having an EPDS $>12$ in the postpartum period, and that seems not only due to worse socio-demo- graphic conditions, contrary to what has appeared in some recent studies (e.g., Rich-Edwards et al, 2006).

Younger women as well as women living without the partner seem to be at risk for depressive symptoms during pregnancy. Women depressed during pregnancy and women who live with the family of origin seem to be at risk for depressive symptoms at 2-3 months postpartum. Furthermore, depression during pregnancy is not only the best predictor for postpartum depression symptoms but also a predictor for postpartum EPDS $>12$, as other authors have pointed out (e.g., Atkinson \& Rickel, 1984; Cooper et al, 1996; Hobfoll et al, 2005; Kitamura et al, 2006; Rich-Edwards et al, 2006). The proportion of the variance of EPDS scores at postpartum accounted for by EPDS scores in late pregnancy was $24.9 \%$, similar to what has been presented in recent studies (Limlomwongse \& Liabsuetrakul, 2006). But, contrary to what has been proposed in the literature, women who are living with the partner are at risk for an EPDS $>12$ during the postpartum, a result that needs further exploration, and may be specific of this sample. However, as presented by O'Hara (1986), the results of this study suggest that different causes may be responsible for prepartum and postpartum depression: the circumstance of living with the partner seems to be protective for depression during pregnancy but a risk factor for depression after delivery. A surprising result that could be explain by the reported difficulties in couples during the transition to parenthood decrease in proximity and communication and the increase in conflicts and ambivalence, resulting in less marital satisfaction and adjustment after when compared to before delivery (Cox et al, 1999; Florsheim et al, 2003; Gloger-Tippelt \& Huerkamp, 1998) - which may be larger and causing a worse impact than partner absence, in this particular sample.

Several epidemiological studies have shown that depression is very common in women during the transition to parenthood, namely when compared to other life phases (e.g., Augusto et al, 1996; Eberhardt-Gran et al, 2003). Following decades of almost exclusive attention to postpartum depression, some recent studies have pointed out that (1) depression may be even more prevalent during pregnancy than in the postpartum period (e.g., Evans et al, 2001; Josefsson et al, 2001; Seimyr et al, 2004), and that (2) pregnancy depression can be the strongest risk factor for postpartum depression (e.g., Kitamura et al, 2006; Rich-Edwards et al, 2006), and have as an adverse impact as postpartum depression on both the mother's (e.g., Marcus et al, 2003; Orr et al, 2002; Pajulo et al, 2001; Zhu \& Valbo, 2002; Zuckerman et al, 
1990 ) and the infant's well-being (Diego et al, 2004; Field et al, 2002; Jones et al, 1998; Lundy et al, 1999; Orr et al, 2002, Zuckerman et al, 1989).

Considering that depression was as prevalent before than after delivery, that almost half of the postpartum depressed women had been depressed since pregnancy, that almost half of the depressed pregnant women will remain depressed during the postpartum period, and that depression during pregnancy is the strongest risk factor for postpartum depression, as others have also pointed out recently (e.g., Da Costa et al., 2000; Evans et al, 2001; Josefsson et al, 2001; Kitamura et al, 2006; Rich-Edwards et al, 2006), screening for depression in pregnancy may be the most adequate measure to identify women at risk and to prevent the adverse effects of depression both before and after childbirth, which are important clinical implications after shown results.

This study was particularly designed to study the impact of socio-demographic variables (particularly age at pregnancy) on the onset of depression during pregnancy and the postpartum period, as well as the impact of pregnancy depression on the onset of postpartum depression. However, other important dimensions have not been considered, which naturally limits the study.

\section{Acknowledgements}

We would like to thank all the mothers who participated in this study. We are also very grateful for the comments of Nine Glangeaud-Freudenthal. This research was supported by a grant from the Calouste Gulbenkian Foundation Human Development and Health Service (Proc. 48914/02-04) and a grant from the Portuguese Foundation for Science and Technology (POCTI/ SAU/14109/1998).

\section{References}

Adouard F, Glangeaud-Freudenthal NM, Golse B (2005) Validation of the Edinburgh postnatal depression scale (EPDS) in a sample of women with high-risk pregnancies in France. Arch Womens Ment Health 8(2): 89-95.

Agoub M, Moussaoui D, Battas O (2005) Prevalence of postpartum depression in a Moroccan sample. Arch Womens Ment Health 8(1): $37-43$.

Andersson L, Sundstrom-Poromaa I, Bixo M, Wulff M, Bondestam K, Strom M (2003) Point prevalence of psychiatric disorders during the second trimester of pregnancy: a population-based study. Am J Obstet Gynecol 189(1): 148-154.

Areias MEG, Kumar R, Barros H, Figueiredo E (1996a) Correlates of postnatal depression in mothers and fathers. Br J Psychiatry 169: $36-41$.

Areias MEG, Kumar R, Barros H, Figueiredo E (1996b) Comparative incidence of depression in women and men, during pregnancy and after childbirth. Validation of the Edinburgh Postnatal Depression Scale in Portuguese mothers. Br J Psychiatry 169(1): 30-35.

Atkinson AK, Rickel AU (1984) Postpartum depression in primiparous parents. J Abnorm Psychol 93(1): 115-119.
Augusto A, Kumar R, Calheiros JM, Matos E, Figueiredo E (1996) Postnatal depression in an urban area of Portugal: comparison of childbearing women and matched controls. Psychol Med 26: 135-141.

Barnet B, Joffe A, Duggan AK, Wilson M, Repke J (1996) Depressive symptoms, stress, and social support in pregnant and postpartum adolescents. Arch Pediatr Adolesc Med 150: 64-69.

Barth RP, Schinke SP, Maxwell JS (1983) Psychological correlates of teenage motherhood. J Youth Adolesc 12: 471-487.

Chung T, Lau T, Yip A, Chiu H, Lee D (2001) Antepartum depressive symptomatology is associated with adverse obstetric and neonatal outcomes. Psychosom Med 63: 830-834.

Colleta ND (1983) At risk for depression: a study of young mothers. J Genet Psychol 142: 301-310.

Cooper PJ, Murray L, Hooper R, West A (1996) The development and validation of a predictive index for postpartum depression. Ann Med Psychol 26(3): 627-634.

Costa R, Pacheco A, Figueiredo B (2007) Prevalence and predictors of postpartum depression. Rev Psiquiat Clínica 34 (in press).

Cox JL, Holden JM, Sagovsky R (1987) Detection of postnatal depression: Development of the 10-item Edinburgh Postnatal Depression Scale. Br J Psychiatry 150: 782-786.

Da Costa D, Larouche J, Dritsa M, Brender W (2000) Psychosocial correlates of prepartum and postpartum depressed mood. J Affect Disord 59(1): 31-40.

Deal LW, Holtz VL (1998) Young maternal age and depressive symptoms: results from the 1988 national maternal and infant health survey. Am J Publ Health 88(2): 266-270.

Diego M, Field T, Hernandez-Reif M, Cullen C, Schanberg S, Kuhn C (2004) Prepartum, postpartum and chronic depression effects on newborns. Psychiatry 67(1): 63-80.

Eberhardt-Gran M, Tambs K, Opjordsmoen S, Skrondal A, Eskild A (2003) A comparison of anxiety and depressive symptomatology in postpartum and non-postpartum women. Soc Psychiatry Psychiatr Epidemiol 38: 551-556.

Evans J, Heron J, Francomb H, Oke S, Golding J (2001) Cohort of depressed mood during pregnancy and after childbirth. Br Med J 323: $257-260$.

Felice E, Saliba J, Grech V, Cox J (2006) Validation of the Maltese version of the Edinburgh Postnatal Depression Scale. Arch Womens Ment Health 9(2): 75-80.

Field T, Diego M, Dieter J, Hernandez-Reif M, Salman F, Schanberg S, Kuhn C, Yando R, Bendell D (2002) Prenatal anger effects on the fetus and neonate. J Obstet Gynaecol 22(3): 260-266.

Figueiredo B (1997) Postpartum depression, mother-infant interaction and child development, $\mathrm{PhD}$ dissertation not published. Universidade do Minho, Braga.

Figueiredo B, Bifulco A, Pacheco A, Costa R, Magarinho R (2006) Teenage pregnancy, attachment style and depression: a comparison of teenage and adult pregnant women in a Portuguese series. Attach Hum Dev 8(2): 123-138.

Gorman L, O'Hara M, Figueiredo B, Hayes S, Jaquemain F, Klier C, Rosi S, Seneviratne G, Sutter-Dallay AL, TCS-PND group (2004) Adaptation of the Structured Clinical Interview for DSM-IV disorder for assessing depression in women during pregnancy and postpartum across countries and cultures. Br J Psychiatry 184 (Suppl. 46): 18-25.

Hobfoll S, Ritter C, Lavin J, Hulsizer M, Cameron R (2005) Depression prevalence and incidence among inner-city pregnant and postpartum women. J Consult Clini Psychol 63(3): 445-453.

Hudson DB, Elek SM, Campbell-Grossman C (2000) Depression, self-esteem, loneliness, and social support in adolescent mothers participating in the New Mothers' Network. Adolescence 35(139): 443-453.

Johanson R, Chapman G, Murray D, Johnson I, Cox J (2000) The North Staffordshire Maternity Hospital prospective study of pregnancyassociated depression. J Psychosom Obstet Gynaecol 21: 93-97. 
Jones N, Field T, Fox N, Davalos M, Lundy B, Hart S (1998) Newborns of mothers with depressive symptoms are physiologically less developed. Infant Behav Develop 28: 59-70.

Josefsson A, Berg G, Nordin C, Sydsjo G (2001) Prevalence of depressive symptoms in late pregnancy and postpartum. Acta Obstet Gynecol Scand 80(3): 251-255.

Kitamura T, Yoshida K, Okano T, Kinoshita K, Hayashi M, Toyoda N, Ito M, Kudo N, Tada K, Kanazawa K, Sakumoto K, Satoh S, Furukawa T, Nakano H (2006) Multicentre prospective study of perinatal depression in Japan: incidence and correlates of antenatal and postnatal depression. Arch Womens Ment Health 9(3): 121-130.

Kumar R, Robson K (1984) A prospective study of emotional disorders in childbearing women. Br J Psychiatry 144: 35-47.

Leadbeater BJR, Linares O (1992) Depressive symptoms and neglect and Puerto Rican adolescent mothers in the first three years postpartum. Dev Psychopathol 4: 451-468.

Limlomwongse N, Liabsuetrakul T (2006) Cohort study of depressive moods in Thai women during late pregnancy and 6-8 weeks of postpartum using the Edinburgh Postnatal Depression Scale (EPDS). Arch Womens Ment Health 9(3): 131-138.

Lindgren K (2001) Relationships among maternal-fetal attachment, prenatal depression, and health practices in pregnancy. Res Nurs Health 24(3): 203-217.

Lundy B, Jones N, Field T, Nearing G, Davalos M, Pietro P, Schanberg S, Kuhn C (1999) Prenatal depression effects on neonates. Infant Behav Develop 22: 119-129.

Marcus S, Flynn H, Blow F, Barry K (2003) Depressive symptoms among pregnant women screened in obstetrics settings. J Womens Health 12(4): 373-380.

McGee R, Williams S, Kashani JH, Silva PA (1983) Prevalence of selfreported depressive symptoms and associated social factors in mothers in Dunedin. Br J Psychiatry 143: 473-479.

McKee MD, Cunningham M, Jankowski KR, Zayas L (2001) Healthrelated functional status in pregnancy: Relationship to depression and social support in a multi-ethnic population. Obstet Gynecol 97(6): 988-993.

Milan S, Ickovics JR, Kershaw T, Lewis J, Meade C, Ethier K (2004) Prevalence, course, and predictors of emotional distress in pregnant and parenting adolescents. J Consult Clin Psychol 72(2): 328-340.

Murray L, Stanley C, Hooper R, King F, Fiori-Cowley A (1996) The role of infant factors in postnatal depression and mother-infant interactions. Dev Med Child Neurol 38: 109-119.

O'Hara MW (1986) Social support, life events, and depression during pregnancy and the puerperium. Arch Gen Psychiatry 43(6): 569-573.

O'Hara MW, Swain AM (1996) Rates and risk of postpartum depression: A meta-analysis. Int Rev Psychiatry 8(1): 37-54.

Onozawa K, Kumar RC, Adams D, Dore C, Glover V (2003) High EPDS scores in women from ethnic minorities living in London. Arch Womens Ment Health 6 Suppl 2: S51-S55.
Orr S, James S, Prince C (2002) Maternal prenatal depressive symptoms and spontaneous preterm births among african-american women in Baltimore, Maryland. Am J Epidemiol 156(9): 797-802.

Pajulo M, Savonlahti E, Sourander A, Helenius H, Piha J (2001) Antenatal depression, substance dependency and social support. J Affect Disord 65: 9-17.

Prodromidis M, Abrams S, Field T, Scafidi F, Rahdert E (1994) Psychosocial stressors among depressed adolescent mothers. Adolescence 29(114): 331-343.

Rich-Edwards JW, Kleinman K, Abrams A, Harlow BL, McLaughlin TJ, Joffe H, Gillman MW (2006) Sociodemographic predictors of antenatal and postpartum depressive symptoms among women in a medical group practice. J Epidemiol Community Health 60(3): 221-227.

Ritter C, Hobfoll SE, Lavin J, Cameron RP, Hulsizer MR (2000) Stress, psychosocial resources, and depressive symptomatology during pregnancy in low-income, inner-city women. Health Psychol 19(6): 576-585.

Ross LE, Gilbert Evans SE, Sellers EM, Romach MK (2003) Measurement issues in postpartum depression part 1: anxiety as a feature of postpartum depression. Arch Womens Ment Health 6(1): 51-57.

Seguin L, Potvin L, St-Denis M, Loiselle J (1995) Chronic stressors, social support, and depression during pregnancy. Obstet Gynecol 85(4): 563-589.

Seimyr L, Edhborg M, Lundh W, Sjogren B (2004) In the shadow of maternal depressed mood: experiences of parenthood during the first year after childbirth. J Psychosom Obstet Gynaecol 25(1): 23-34.

Schmidt RM, Wiemann CM, Rickert VI, Smith EO (2006) Moderate to severe depressive symptoms among adolescent mothers followed four years postpartum. J Adolesc Health 38(6): 712-718.

Troutman BR, Cutrona CE (1990) Nonpsychotic postpartum depression among adolescent mothers. J Abnorm Psychol 99: 69-78.

Verkerk GJ, Pop VJ, Van Son MJ, Van Heck GL (2003) Prediction of depression in the postpartum period: a longitudinal follow-up study in high-risk and low-risk women. J Affect Disord 77(2): 159-166.

Zhu S, Valbo A (2002) Depression and smoking during pregnancy. Addict Behav 27: 649-658.

Zuckerman B, Amaro H, Bauchner H, Cabral H (1989) Depressive symptoms during pregnancy: Relationship to poor health behaviours. Am J Obstet Gynecol 160: 1107-1111.

Zuckerman B, Bauchner H, Parker S, Cabral H (1990) Maternal depressive symptoms during pregnancy, and newborn irritability. J Dev Behav Pediatr 11(4): 190-194.

Correspondence: Bárbara Figueiredo, Department of Psychology, University of Minho, Campus de Gualtar, 4710-057 Braga, Portugal; e-mail: bbfi@iep.uminho.pt 